\title{
Residential mobility among adult cancer survivors in the United States
}

\author{
Bian Liu ${ }^{1 *} \mathbb{D}$, Furrina F. Lee ${ }^{2}$ and Francis Boscoe ${ }^{3}$
}

\begin{abstract}
Background: While residential mobility affects people's health, the dynamic of neighborhood tenure and its associated factors among cancer patients and survivors have not been studied in detail. This cross-sectional study aimed to identify sociodemographic factors associated with neighborhood tenure and relocation after the first cancer diagnosis among U.S. adult cancer survivors and patients.

Methods: Based on a nationally representative sample of non-institutionalized civilian adults ( $\geq 18$ years, $n=185,637$ ) from the 2013-2018 National Health Interview Survey, we compared neighborhood tenure between adults with and without a history of cancer, and identified factors associated with their neighborhood tenure and relocation after the first cancer diagnosis, using propensity score matching, and logistic regression models with survey design incorporated.

Results: Among adults with cancer (9.0\%), 39.6\% had a neighborhood tenure $\leq 10$ years (vs. $61.2 \%$ among those without cancer), and $25.6 \%$ (equivalent to 5.4 million) relocated after their first cancer diagnosis. The odds of having shorter neighborhood tenure was higher among the cancer group in the propensity-matched samples (odds ratio = 1.05; 95\% Cl: 1.05-1.06; $n=17,259$ ). Among cancer survivors, the odds of neighborhood relocation were negatively associated with increasing age, perceived neighborhood social cohesion, having high school level education, and being married; while positively associated with having family income below the poverty threshold, being uninsured, and living in non-Northeast regions.

Conclusions: High residential mobility was found among a sizable proportion of adults with a history of cancer, and was associated with multiple socioeconomic factors. Incorporating and addressing modifiable risk factors associated with residential mobility among cancer patients and survivors may offer new intervention opportunities to improve cancer care delivery and reduce cancer disparities.
\end{abstract}

Keywords: Cancer survivorship, Residential mobility, Neighborhood tenure, Relocation, Cancer disparities

\section{Introduction}

The places people reside throughout their lives play an important role in their health-related behaviors and their propensity to develop diseases [1]. While socioeconomic status (SES), demographic factors, environmental exposure conditions, and access to healthcare in the neighborhoods in which people reside are recognized as critical

\footnotetext{
* Correspondence: bian.liu@mountsinai.org

'Department of Population Health Science and Policy, Icahn School of Medicine at Mount Sinai, One Gustave L. Levy Place, Box 1077, New York City, NY 10029, USA

Full list of author information is available at the end of the article
}

elements in promoting health and health equity $[2,3]$, the geospatial context of health and place has not been routinely incorporated in health research and healthcare delivery $[4,5]$. In studies that have incorporated neighborhood level factors, the emphasis has largely been on the current place of residence, while little information is available regarding residential mobility, particularly in the context of cancer.

A cancer diagnosis may trigger relocation for a variety of reasons which may have a positive or negative impact on care delivery and coordination, quality of life, and ultimately survival. Relocation has been used as a proxy

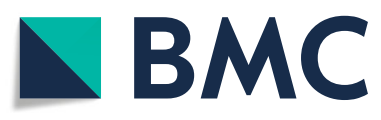

(c) The Author(s). 2020 Open Access This article is licensed under a Creative Commons Attribution 4.0 International License, which permits use, sharing, adaptation, distribution and reproduction in any medium or format, as long as you give appropriate credit to the original author(s) and the source, provide a link to the Creative Commons licence, and indicate if changes were made. The images or other third party material in this article are included in the article's Creative Commons licence, unless indicated otherwise in a credit line to the material. If material is not included in the article's Creative Commons licence and your intended use is not permitted by statutory regulation or exceeds the permitted use, you will need to obtain permission directly from the copyright holder. To view a copy of this licence, visit http://creativecommons.org/licenses/by/4.0/ The Creative Commons Public Domain Dedication waiver (http://creativecommons.org/publicdomain/zero/1.0/) applies to the data made available in this article, unless otherwise stated in a credit line to the data. 
for household financial hardship, disruption of care continuity, and disruption of social networks, all of which carry negative impacts to health and psychosocial wellbeing, as well as survival of cancer patients [6-8]. Relocation has been found to be associated with an increased rate of late stage cancer diagnosis and an increased risk of 10-year cancer-specific mortality based on cancer registry data [6]. Geographic mobility has also been used as a proxy for social re-integration and the morbidity burden associated with mortality among survivors of childhood cancer [9]. In addition age, sex, and SES were found to be associated with mobility regardless of cancer type and relapse status [9]. Despite the potential influence of residential mobility on cancer care and survival, we know little about the dynamic patterns of relocation, reasons for relocation, and their subsequent effects on a variety of health outcomes among cancer patients and survivors.

To address these knowledge gaps, we used data from the National Health Interview Survey (NHIS) to understand residential mobility for a representative sample of the noninstitutionalized U.S. civilian adult population. We aimed to compare neighborhood tenure between those with and without a history of cancer and identify sociodemographic factors associated with neighborhood tenure and relocation after the first cancer diagnosis. To the best of our knowledge, this is the first estimate of residential mobility among the non-institutionalized civilian adult population with and without cancer and identified sociodemographic factors influencing their residential mobility. Understanding these residential history patterns and risk factors, particularly modifiable ones, among cancer survivors is a first step towards a better assessment of the unmet needs among this vulnerable population. With continued growth of the cancer survivor population [10,11], results from this study may provide novel insights into improving coordinated cancer care continuity for cancer survivors and reducing cancer disparities.

\section{Methods}

\section{Data source and participants}

We combined the most recent publicly available NHIS data from 2013 to 2018. NHIS is an ongoing cross-sectional household interview survey providing primary data for monitoring health and tracking progress toward achieving national health objectives [12]. Through a multistage probability clustering and stratification design, NHIS provides a national representative sample of the non-institutionalized civilian population in the United States. We included 185,637 adults aged 18 years and older who had both information on their neighborhood tenure and history of cancer. The neighborhood tenure information has been part of NHIS since 2013. Responses of "refused", "unknown", or "not ascertained" were treated as missing and were excluded $(n=4476)$ from the study population sample analytic domain.

\section{Outcome variables}

The first main outcome was neighborhood tenure. Participants were asked "About how long have you lived in your present neighborhood?", and the responses were categorized into 5 levels: less than 1 year, 1-3 years, 410 years, $11-20$ years, and more than 20 years.

The second main outcome was neighborhood relocation after the first cancer diagnosis. We defined those who answered yes to the question "Ever told by a doctor you had cancer" as having a history of cancer. Among those with cancer, detailed questions were asked about their cancer types (up to 30 sites) and their corresponding age at cancer diagnosis. We subsequently derived the time since cancer diagnosis by subtracting age at the interview and age at the first cancer diagnosis. We categorized time since cancer diagnosis into 5 levels to match the neighborhood tenure variable. Cancer survivors were considered as having moved if their neighborhood tenure was less than their time elapsed since cancer diagnosis, and having stayed in the same neighborhood if either their time since cancer diagnosis and neighborhood tenure were in the same time duration category or if neighborhood tenure was greater than the time since cancer diagnosis.

\section{Covariates}

We included the following sociodemographic variables: age at the interview, sex, race, Hispanic ethnicity, education, marital status, employment status, ratio of family income to the poverty threshold, health insurance coverage, residence region, nativity, family size, having family members aged 65 years and over, and having family members under 18 years of age.

We also included a measure of perceived neighborhood social cohesion (pNSC), which was assessed from four conceptually related questions [13]. Participants were asked how much they agree or disagree with the following statements about their neighborhoods: 1) "People in this neighborhood help each other out"; 2) "There are people I can count on in this neighborhood"; 3) "People in this neighborhood can be trusted"; 4) "This is a close-knit neighborhood". The responses were on a 4-point scale: 1 , definitely agree; 2 , somewhat agree; 3 , somewhat disagree; and 4 , definitely disagree. We reverse coded the scale and summed the scores from the four questions, so that a higher total score indicated higher pNSC. These four questions have been used in other studies both on their own and in addition to a fifth question ("people in this neighborhood generally don't get along with each other", which was not asked in NHIS) to assess health behavior and sociological characteristics at individual and neighborhood levels [13, 14].

\section{Statistical analysis}

We used survey procedures in SAS (V9.4) to take into account the complex NHIS sample design. Bivariate analyses were conducted to compare differences in neighborhood 
tenure and categorical covariates between participants with and without cancer using Rao-Scott Chi-Square tests in the proc surveyfreq procedure and the proc surveymean procedure for the two continuous variables, age and pNSC score. The distribution of neighborhood tenure and relocation after the first cancer diagnosis by major cancer types are presented as Supplemental Information (SI) in Table S1.

At the multivariable level, we used the proc surveylogistic procedure to fit a cumulative logit model to compare neighborhood tenure (a 5-level ordinal variable) separately for the cancer and non-cancer groups. In an attempt to adjust for confounders, we compared the differences in neighborhood tenure between cancer and non-cancer pairs identified from propensity score matching (PSM) algorithms on all 15 covariates $[15,16]$. For completeness, we present the comparisons of the study population characteristics before and after PSM in Table S2 and the analysis without PSM in Table S3. Among those with a history of cancer, we fitted a binary logit model to identify factors associated with neighborhood relocation after the first cancer diagnosis. All models were adjusted for relevant covariates (unless otherwise specified), which were selected using forward selection steps (entry significance level $=0.05)$ in an unweighted model before inclusion in the final model. Unless otherwise noted, we report the adjusted odds ratio (aOR and 95\% confidence interval, $\mathrm{CI}$ ).

We also conducted a sensitivity analysis to identify factors associated with neighborhood relocation among a subset of cancer survivors by excluding those whose time since cancer diagnosis and neighborhood tenure were in the same time duration category, as there might be misclassification of their relocation status due to constraints of the available time resolution in the data. For example, in the scenario where the time since the first cancer diagnosis and neighborhood tenure were both 4-10 years, an actual 8-year time since cancer diagnosis and a 4-year neighborhood tenure would imply relocation.

\section{Results}

General characteristics of the study population (Table 1) Of the 185,637 adults from the 2013-2018 NHIS (equivalent to a weighted $237,683,583$ persons), $9 \%$ (equivalent to 21,354 , 205 persons) had a self-reported history of cancer. All the covariates differed significantly between those with and without a history of cancer. The weighted mean age of all samples was 47.2 years (median: 46.1 years), and participants with a history of cancer were older than their non-cancer counterparts (mean 64.5 vs. 45.5 years). A majority (86.7\%) of cancer survivors reported having only one cancer, with major types being skin (non-melanoma 13.7\%; melanoma 5.8\%, and other 5.3\%), breast $(21.6 \%)$, prostate $(10.7 \%)$, colon $(5.4 \%)$, other $(4.8 \%)$, cervix (4.6\%), bladder (4.0\%), lymphoma (3.5), thyroid (3.4\%), uterus $(2.6 \%)$, kidney (2.5\%), ovary (2.2\%), and lung (2.1\%).
The proportions of neighborhood tenure of $<1$ year, $1-3$ years, and 4-10 years among those with cancer were $6.4,12.5$, and $20.7 \%$, respectively. Overall, $59.3 \%$ of the adults had resided in their neighborhood for 10 years or less, and the proportion was lower among those with than without cancer (39.6\% vs. 61.2\%). The proportion of those with cancer living in their neighborhood for more than 20 years nearly doubled that of those without cancer (39.2\% vs. 19.6\%). Approximately a quarter (25.6\%, equivalent to $5,394,374$ persons) of the adult cancer survivors relocated after their first cancer diagnosis. As shown in the supplemental Table S1, the proportion of having a neighborhood tenure $<1$ year was the lowest among participants with a history of lung cancer (3.9\%) while highest among those with cervical cancer. The proportion of relocation after the first cancer diagnosis was consistently the highest in cervical cancer (56.7\%) and lowest in lung cancer (13.1\%).

\section{Factors associated with shorter neighborhood tenure (Tables 2-3)}

A similar set of factors affecting neighborhood tenure was found for both participants with and without a history of cancer (Table 2). Significant factors that were positively associated with a shorter neighborhood tenure regardless of cancer history status included: having below- poverty family income, no health insurance coverage, residing outside of the Northeast region, having a family size smaller than three, and having children in the family. On the other hand, factors negatively associated with a shorter neighborhood tenure that were shared by participants with and without a cancer history included: increasing age, having education attainment less than or equivalent to high school, being US-born, and having high perceived neighborhood social cohesion. Our analyses showed that employment status had an opposite impact on neighborhood tenure between those with and without a history of cancer. Not working/not looking-for-work (compared to working) was associated with increased odds of shorter neighborhood tenure among participants with a history of cancer $(\mathrm{aOR}=1.15$; 95\%CI: 1.05-1.26), which was contrary to what was found among adults without a cancer history $(\mathrm{aOR}=$ 0.93; 95\%CI: 0.90-0.96).

To reduce the bias in our estimate, we identified 17,259 matched cancer/non-cancer pairs ( 90\% of the 19,105 cancer cases, Table 3) based on their propensity scores on all 15 covariates. In this matched subset, we found that the odds of shorter tenure among cancer patients were higher than their non-cancer counterparts (unadjusted OR = 1.05; 95\% CI: 1.05-1.06, Table 3), which was contrary to the trend found prior to PSM (unadjusted OR $=0.40 ; 95 \% \mathrm{CI}$ : $0.39-0.42 ; n=185,637$, Table 3). 
Table 1 Distributions of the study population characteristics overall and by cancer history status, NHIS 2013-2018

\begin{tabular}{|c|c|c|c|c|c|c|}
\hline \multirow[t]{2}{*}{ Variables } & \multicolumn{2}{|c|}{ Overall $(185,637,100 \%)$} & \multicolumn{2}{|c|}{$\begin{array}{l}\text { With a history of cancer }(19,105 \text {, } \\
9.0 \%)\end{array}$} & \multicolumn{2}{|c|}{$\begin{array}{l}\text { Without a history of cancer (166, } \\
532,91.0 \%)\end{array}$} \\
\hline & Unweighted $\mathrm{N}$ & Weighted \% & Unweighted $\mathrm{N}$ & Weighted \% & Unweighted $\mathrm{N}$ & Weighted \% \\
\hline \multicolumn{7}{|c|}{ Neighborhood tenure (years) } \\
\hline$<1$ & 25,568 & 13.1 & 1279 & 6.4 & 24,289 & 13.7 \\
\hline $1-3$ & 39,048 & 20.9 & 2405 & 12.5 & 36,643 & 21.7 \\
\hline $4-10$ & 46,057 & 25.3 & 4028 & 20.7 & 42,029 & 25.8 \\
\hline $11-20$ & 32,886 & 19.3 & 3875 & 21.2 & 29,011 & 19.2 \\
\hline$>20$ & 42,078 & 21.4 & 7518 & 39.2 & 34,560 & 19.6 \\
\hline \multicolumn{7}{|c|}{ Time since the 1st cancer diagnosis (years) } \\
\hline$<1$ & & & 1270 & 6.3 & & \\
\hline $1-3$ & & & 2394 & 12.5 & & \\
\hline $4-10$ & & & 4015 & 20.7 & & \\
\hline $11-20$ & & & 3857 & 21.2 & & \\
\hline$>20$ & & & 7489 & 39.2 & & \\
\hline
\end{tabular}

Having changed neighborhoods after the 1st cancer diagnosis

$\begin{array}{lll}\text { No } & 13,754 & 74.4 \\ \text { Yes } & 5087 & 25.6\end{array}$

Sex

$\begin{array}{lllllll}\text { Male } & 83,589 & 48.2 & 7890 & 43.9 & 75,699 & 48.7 \\ \text { Female } & 102,048 & 51.8 & 11,215 & 56.1 & 90,833 & 51.3\end{array}$

Race

$\begin{array}{lllllll}\text { white only } & 144,910 & 78.8 & 16,858 & 89.4 & 128,052 & 77.7 \\ \text { black only } & 24,018 & 12.1 & 1391 & 6.3 & 22,627 & 12.7 \\ \text { AlAN only } & 2033 & 1.0 & 114 & 0.5 & 1919 & 1.0 \\ \text { Asian only } & 10,422 & 6.0 & 395 & 2.3 & 10,027 & 6.4 \\ \text { other } & 4254 & 2.1 & 347 & 1.5 & 3907 & 2.1\end{array}$

Hispanic ethnicity

$\begin{array}{lllllll}\text { No } & 158,443 & 84.3 & 18,035 & 94.3 & 140,408 & 83.3 \\ \text { Yes } & 27,194 & 15.7 & 1070 & 5.7 & 26,124 & 16.7\end{array}$

\section{Education}

$$
\begin{aligned}
& <\text { high school } \\
& \text { high school } \\
& >\text { high school }
\end{aligned}
$$

$24,605 \quad 12.5$

2380

11.0

22,225

12.7

46,359

25.0

4851

25.3

41,508

25.0

113,971

62.5

11,813

63.7

102,158

62.3

Marital status

other

$103,677 \quad 47.1$

10,157

39.3

93,520

47.9

Yes

81,960

52.9

8948

60.7

73,012

52.1

Employment status

$\begin{array}{ll}\text { Working } & 107,570 \\ \text { Looking for work } & 7088 \\ \text { Not working/ not looking for work } & 70,906\end{array}$

61.8

6164

35.8

101,406

64.3

4.2

291

1.6

6797

4.4

Ratio of family income to the poverty threshold

$<1$

27,283

12.5

1972

62.6

58,262 
Table 1 Distributions of the study population characteristics overall and by cancer history status, NHIS 2013-2018 (Continued)

\begin{tabular}{|c|c|c|c|c|c|c|}
\hline \multirow[t]{2}{*}{ Variables } & \multicolumn{2}{|c|}{ Overall $(185,637,100 \%)$} & \multicolumn{2}{|c|}{$\begin{array}{l}\text { With a history of cancer }(19,105 \text {, } \\
9.0 \%)\end{array}$} & \multicolumn{2}{|c|}{$\begin{array}{l}\text { Without a history of cancer (166, } \\
532,91.0 \%)\end{array}$} \\
\hline & Unweighted $\mathrm{N}$ & Weighted \% & Unweighted $\mathrm{N}$ & Weighted \% & Unweighted $\mathrm{N}$ & Weighted \% \\
\hline$\geq 4$ & 61,987 & 40.7 & 6943 & 46.1 & 55,044 & 40.1 \\
\hline \multicolumn{7}{|c|}{ Health insurance coverage } \\
\hline No & 21,367 & 11.7 & 644 & 3.5 & 20,723 & 12.5 \\
\hline Yes & 163,589 & 88.3 & 18,437 & 96.5 & 145,152 & 87.5 \\
\hline \multicolumn{7}{|c|}{ Residence region } \\
\hline Northeast & 30,395 & 17.6 & 3291 & 17.8 & 27,104 & 17.6 \\
\hline Midwest & 40,667 & 22.4 & 4444 & 23.5 & 36,223 & 22.2 \\
\hline South & 66,267 & 36.6 & 6733 & 37.6 & 59,534 & 36.5 \\
\hline West & 48,308 & 23.4 & 4637 & 21.1 & 43,671 & 23.6 \\
\hline
\end{tabular}

Nativity

\section{Otherwise}

US born

Family size

$\begin{array}{rr}1 & 64,372 \\ 2 & 59,669 \\ \geq 3 & 61,596\end{array}$

\section{1,407}

154,230

64,372

59,669
131,120

54,517
19.6

33.6

46.8

No

Yes

Having family members aged 18 and younger

$\begin{array}{ll}\text { No } & 132,183 \\ \text { Yes } & 53,454\end{array}$

\section{People in neighborhood help each other}

$\begin{array}{lll}\text { Definitely agree } & 72,301 & 39.4 \\ \text { Somewhat agree } & 75,271 & 43.2 \\ \text { Somewhat disagree } & 18,849 & 10.4 \\ \text { Definitely disagree } & 13,275 & 7.0\end{array}$

There are people I can count on in this neighborhood

Definitely agree

89,638

49.0

Somewhat agree

58,230

17,309

Somewhat disagree

15,412

73.9

26.1

65.3

34.7

18.6

33.1

9.6

8.3

People in neighborhood can be trusted

$$
\begin{aligned}
& \text { Definitely agree } \\
& \text { Somewhat agree } \\
& \text { Somewhat disagree }
\end{aligned}
$$

Definitely disagree

82,867

65,350

17,530

13,525

46.1
37.3
9.4
72

This is a close-knit neighborhood

Definitely agree
Somewhat agree
Somewhat disagree
Definitely disagree

52,150

28.3

63,194

36.0

37,914

21.2

26,981

14.5
1411

17,694

7936

8222

2947

6957

12,148

16,995

2110

8898

6885

1589

1254

11,088
5035
1324
1268

\section{3}

91.7

24.8

50.3

24.9

40.3

59.7

85.4

14.6

46.8

38.4

8.6

6.2

58.5

27.8

7.2

6.4

10,407

5745

1293

1088

6196

6222

3611

2657

\section{0}

31.8

6.8

5.4

32.3

34.1

19.6

14.0
29,996

136,536

19.6

80.4

56,436

19.1

51,447

32.0

48.9

58,649

124,163

77.3

42,369

22.7

115,188

63.3

51,344

36.7

38.7

43.6

10.5

7.1

12,021

78,550

48.0

53,195

15,985

14,144

33.7

9.8

8.5

45.1

37.8

9.6

7.4

12,437

45,954

27.9

56,972

36.2

21.3

14.6 
Table 1 Distributions of the study population characteristics overall and by cancer history status, NHIS 2013-2018 (Continued)

\begin{tabular}{|c|c|c|c|c|c|c|}
\hline \multirow[t]{2}{*}{ Variables } & \multicolumn{2}{|c|}{ Overall $(185,637,100 \%)$} & \multicolumn{2}{|c|}{$\begin{array}{l}\text { With a history of cancer }(19,105 \text {, } \\
9.0 \%)\end{array}$} & \multicolumn{2}{|c|}{$\begin{array}{l}\text { Without a history of cancer (166, } \\
532,91.0 \%)\end{array}$} \\
\hline & Unweighted $\mathrm{N}$ & Weighted \% & Unweighted $\mathrm{N}$ & Weighted \% & Unweighted $\mathrm{N}$ & Weighted \% \\
\hline Weighted measures & Mean & Median (IQR) & Mean & Median (IQR) & Mean & Median (IQR) \\
\hline \multicolumn{7}{|l|}{ Age (years) } \\
\hline & 47.2 & $46.1(31.2-60.5)$ & 64.5 & $65.5(55.6-74.5)$ & 45.5 & $43.9(30.0-58.2)$ \\
\hline \multicolumn{7}{|c|}{ Perceived neighborhood social cohesion score } \\
\hline & 12.2 & $12(9.9-14.7)$ & 12.7 & $12.9(10.5-15.0)$ & 12.1 & $11.9(9.8-14.7)$ \\
\hline
\end{tabular}

Note: We applied survey procedures to take into account the NHIS sample design and to obtain the population weighted proportion (\%) for categorical variables, and the population weighted mean, median, and interquartile range (IQR) for continuous variables. All covariates differ significantly by cancer status based on Rao-Scott Chi-Square tests for categorical variables with a $p$-value of $<0.0001$, and survey regressions for continuous variables $(p$-value $<0.0001)$. AlAN $=$ American Indian and Alaskan Native

Table 2 Factors associated with shorter neighborhood tenure among those with and without a history of cancer, NHIS 2013-2018

\begin{tabular}{|c|c|c|}
\hline Variables & $\begin{array}{l}\text { With a history of cancer } \\
\text { Adjusted OR }(95 \% \mathrm{CI})\end{array}$ & $\begin{array}{l}\text { Without a history of cancer } \\
\text { Adjusted OR }(95 \% \mathrm{Cl})\end{array}$ \\
\hline Age (years) & $0.95(0.95-0.96)$ & $0.95(0.94-0.95)$ \\
\hline Race: black only vs. white only & $1.03(0.89-1.19)$ & $1.01(0.97-1.06)$ \\
\hline AIAN only vs. white only & $0.92(0.63-1.33)$ & $0.83(0.67-1.04)$ \\
\hline Asian only vs. white only & $0.89(0.69-1.16)$ & $1.06(1.00-1.13)$ \\
\hline Other vs. white only & $1.18(0.90-1.53)$ & $0.99(0.91-1.09)$ \\
\hline Hispanic ethnicity: Yes vs. No & $0.94(0.79-1.11)$ & $0.80(0.76-0.85)$ \\
\hline Education: < vs. > High school & $0.82(0.73-0.93)$ & $0.76(0.72-0.80)$ \\
\hline$=$ vs. $>$ High school & $0.82(0.75-0.91)$ & $0.79(0.76-0.82)$ \\
\hline Employment status: Looking for work vs. working & $0.94(0.71-1.24)$ & $0.96(0.89-1.03)$ \\
\hline Not looking for work/not working vs. working & $1.15(1.05-1.26)$ & $0.93(0.90-0.96)$ \\
\hline Ratio of family income to the poverty threshold: $<1$ vs. $\geq 4$ & $1.58(1.38-1.81)$ & $1.60(1.51-1.68)$ \\
\hline $1-1.99$ vs. $\geq 4$ & $1.16(1.03-1.30)$ & $1.30(1.25-1.35)$ \\
\hline $2-3.99$ vs. $\geq 4$ & $0.99(0.90-1.09)$ & $1.09(1.06-1.13)$ \\
\hline Health insurance coverage: Not covered vs. Covered & $1.17(0.96-1.43)$ & $1.12(1.08-1.17)$ \\
\hline Residence region: Midwest vs. Northeast & $1.44(1.25-1.67)$ & $1.38(1.30-1.46)$ \\
\hline South vs. Northeast & $1.54(1.35-1.77)$ & $1.60(1.51-1.70)$ \\
\hline West vs. Northeast & $1.80(1.56-2.08)$ & $1.62(1.53-1.72)$ \\
\hline Nativity: US-born vs. otherwise & $0.69(0.60-0.79)$ & $0.64(0.61-0.67)$ \\
\hline Family size: 1 vs. $\geq 3$ & $1.92(1.64-2.25)$ & $3.72(3.53-3.92)$ \\
\hline 2 vs. $\geq 3$ & $1.31(1.13-1.52)$ & $2.37(2.26-2.49)$ \\
\hline Having family members aged 18 and younger: Yes vs. No & $1.83(1.53-2.20)$ & $2.07(1.97-2.17)$ \\
\hline Perceived neighborhood social cohesion & $0.96(0.95-0.97)$ & $0.93(0.93-0.94)$ \\
\hline
\end{tabular}

Notes: The response variable, neighborhood tenure, was a 5-level ordinal variable: less than 1 year $(n=1091), 1-3$ years $(n=2201), 4-10$ years $(n=3692), 11-20$ years $(n=3557)$, and more than 20 years $(n=6718)$ among those with cancer; the corresponding sample sizes among those without cancer were $21,574,34,090$, $38,919,26,503$, and 30,964 . The total crude sample size was 17,259 and 152,050 for those with and without cancer, respectively. Covariates were selected using forward selection steps (entry significance level $=0.05$ ) in an unweighted model before included in the final model, where we applied survey procedures to take into account NHIS sample design 
Table 3 Comparisons in the odds of shorter neighborhood tenure between models on data before and after the propensity-scorematch

\begin{tabular}{|c|c|c|}
\hline Before matching & Crude odds ratio $(95 \% \mathrm{Cl})$ & $0.40(0.39-0.42)$ \\
\hline Neighborhood Tenure & Unweighted frequency Total (Cancer / non-Cancer) & *Weighted \% for Cancer / non-Cancer \\
\hline Less than 1 year & $25,568(1279 / 24,289)$ & $6.4 / 13.7$ \\
\hline $1-3$ years & $39,048(2405 / 36,643)$ & $12.5 / 21.7$ \\
\hline $4-10$ years & $46,057(4028 / 42,029)$ & $20.7 / 25.8$ \\
\hline $11-20$ years & $32,886(3875 / 29,011)$ & $21.2 / 19.2$ \\
\hline More than 20 years & $42,078(7518 / 34,560)$ & $39.2 / 19.6$ \\
\hline After Matching & Crude odds ratio $(95 \% \mathrm{Cl})$ & $1.05(1.047-1.06)$ \\
\hline Neighborhood Tenure & Unweighted frequency Total (Cancer / non-Cancer) & *Weighted \% for Cancer / non-Cancer \\
\hline Less than 1 year & $2130(1091 / 1039)$ & $5.9 / 5.6$ \\
\hline $1-3$ years & $4323(2201 / 2122)$ & $12.9 / 12.2$ \\
\hline $4-10$ years & 7350 (3692/ 3658) & $21.0 / 20.9$ \\
\hline $11-20$ years & $7098(3557 / 3541)$ & $21.6 / 21.6$ \\
\hline More than 20 years & 13,617 (6718/6899) & $38.6 / 39.8$ \\
\hline
\end{tabular}

Notes: The crude odds of shorter neighborhood tenure was based on a cumulative logit model using the surveylogistic procedure, where the response variable was neighborhood tenure, which was a 5-level ordinal variable (Reference $=$ More than 20 years), and the explanatory variable was cancer history status (Yes vs. No). We conducted propensity-score-match using a one-to-one nearest-neighbor matching algorithm that pairs participants with closest probability (caliper $=0.25$ ) of having a history of cancer, which were conditioned on the following 15 covariates: age, sex, race, Hispanic ethnicity, education, marital status, employment status, income, health insurance coverage status, residence region, birth place, family size, having family member aged 65 and older, having family member aged 18 and younger, and perceived neighborhood social cohesion, from the survey logistic model. We matched 17,259 participants, which was $90.3 \%$ of all 19,105 available cancer samples. We then applied the surveylogistic procedure to the matched samples. The standard differences of the 15 variables prior to and postmatching ranged from -0.5 to 1.1 , and from -0.04 to -0.08 , respectively (details in Table $\mathrm{S} 2$ ). ${ }^{*}$, row percent. The proportional odds assumption was met

Table 4 Factors associated with neighborhood relocation after first cancer diagnosis

\begin{tabular}{|c|c|}
\hline Variables & Adjusted Odds Ratio $(95 \% \mathrm{Cl})$ \\
\hline Age (years) & $0.98(0.97-0.98)$ \\
\hline Sex: Male vs. Female & $0.76(0.69-0.84)$ \\
\hline Race: black only vs. white only & $0.91(0.76-1.10)$ \\
\hline AIAN only vs. white only & $0.51(0.26-1.01)$ \\
\hline Asian only vs. white only & $0.79(0.56-1.12)$ \\
\hline Other vs. white only & $1.07(0.76-1.49)$ \\
\hline Hispanic ethnicity: Yes vs. No & $0.88(0.71-1.10)$ \\
\hline Education: < vs. > High school & $0.88(0.76-1.03)$ \\
\hline$=$ vs. $>$ High school & $0.84(0.75-0.94)$ \\
\hline Marital status: Yes vs. otherwise & $0.64(0.58-0.71)$ \\
\hline Employment status: Looking for work vs. working & $0.90(0.63-1.29)$ \\
\hline Not looking for work/not working vs. working & $1.12(1.00-1.26)$ \\
\hline Ratio of family income to the poverty threshold: $<1$ vs. $\geq 4$ & $1.37(1.15-1.63)$ \\
\hline $1-1.99$ vs. $\geq 4$ & $1.10(0.95-1.28)$ \\
\hline $2-3.99$ vs. $\geq 4$ & $1.00(0.88-1.12)$ \\
\hline Health insurance coverage: Not covered vs. Covered & $1.52(1.20-1.93)$ \\
\hline Residence region: Midwest vs. Northeast & $1.42(1.20-1.67)$ \\
\hline South vs. Northeast & $1.41(1.21-1.65)$ \\
\hline West vs. Northeast & $1.65(1.40-1.94)$ \\
\hline Perceived neighborhood social cohesion & $0.97(0.95-0.98)$ \\
\hline
\end{tabular}

Notes: The response variable was the status of having changed neighborhoods after cancer diagnosis (Yes/No: 4583/12495, total crude sample size $n=17,078$ ). Covariates were selected using forward selection steps (entry significance level $=0.05$ ) in an unweighted model before inclusion in the final model, where we applied survey procedures to take into account NHIS sample design. AlAN = American Indian and Alaskan Native 
In models without PSM, the adjusted model from the full sample $(n=169,309)$ showed that participants with a history of cancer did not differ significantly in their neighborhood tenure from their counterparts without cancer $(\mathrm{aOR}=1.01$; 95\% CI: 0.97-1.06; Supplement Table S3). A similar set of significant covariates that were positively associated with shorter neighborhood tenure (Table S3) were low family income, no health insurance coverage, residing in non-Northeastern regions, smaller family size, and having children in the family, while advanced age, Hispanic ethnicity, low education level, being unemployed, being born in the US, and having a high level of perceived neighborhood social cohesion were significantly inversely associated with shorter neighborhood tenure.

Factors associated with neighborhood relocation after the first cancer diagnosis (Table 4)

The odds of neighborhood relocation decreased with both increasing age $(\mathrm{aOR}=0.98 ; 95 \% \mathrm{CI}: 0.97-0.98)$ and increasing pNSC scores ( $\mathrm{aOR}=0.97$; 95\%CI: 0.95-0.98). The odds of having moved were also lower among males than females $(\mathrm{aOR}=0.76 ;$ 95\%CI: 0.69-0.84), lower among those with a high school level education compared to those with above high school education $(\mathrm{aOR}=0.84$; 95\%CI: 0.75-0.94), and lower among those who were married $(\mathrm{aOR}=0.64 ; 95 \% \mathrm{CI}$ : $0.58-0.71)$. On the other hand, the odds of relocation increased among those with family income below the poverty threshold $(\mathrm{aOR}=1.37$; $95 \% \mathrm{CI}$ : 1.15-1.63), having no health insurance ( $\mathrm{aOR}=1.52$; 95\% CI: $1.20-1.93)$, and residing in non-Northeast regions. We found generally similar results in the sensitivity analysis excluding adults whose time since cancer diagnosis and neighborhood tenure were in the same time duration category (Table S4). For example, the odds of relocation were significantly lower with age $(\mathrm{aOR}=0.97 ; 95 \% \mathrm{CI}$ : 0.97-0.98) and pNSC scores $(\mathrm{aOR}=0.96$; 95\%CI: $0.95-$ 0.98), among males (aOR $=0.72 ;$ 95\%CI: 0.65-0.80), among those with high school education $(\mathrm{aOR}=0.80$; 95\%CI: 0.71-0.91), and among those who were married $(\mathrm{aOR}=0.59 ; 95 \% \mathrm{CI}: 0.53-0.65)$. Significantly increased odds of relocation were found among those who were not in the labor force $(\mathrm{aOR}=1.14 ; 95 \% \mathrm{CI}$ : $1.01-1.29)$, without health insurance coverage $(\mathrm{aOR}=1.60 ; 95 \% \mathrm{CI}: 1.21-1.80)$, and residing outside of the Northeast region.

\section{Discussion}

Little is known about residential mobility and its associated risk factors among cancer survivors and people in general despite the fact that neighborhood environment plays a critical role in people's health and their healthrelated behaviors. Based on a large nationally representative sample, we presented a first estimate of residential mobility among the non-institutionalized civilian adult population with and without cancer, and identified sociodemographic factors influencing their residential mobility. Our results provide new insights into incorporating the spatiotemporal contexts of where people live into health research in general, and among vulnerable subpopulation groups such as cancer survivors.

We found that a quarter of the US non-institutionalized civilian adults had a neighborhood tenure between 4 and 10 years, and 59\% had resided in their neighborhood for less than 10 years. Our findings of the general residential tenure are aligned with the estimates from the U.S. Census, which showed that the average 5-year moving rate in the U.S. population was approximately $35 \%$ and the median residence duration was approximately 5 years $[17,18]$. The percentage of $<$ 1 year neighborhood tenure was $13.1 \%$ overall, which is similar to that found in the general population based on census data, where $11.7 \%$ of the US population (35.9 million) had moved between 2012 and 2013 [19]. The proportion of moving for "health reasons" was small in the census data, and was collapsed into the "other" category, which only represented $2.3 \%$ of the sample, while the three major reasons for moving were family-related (30.3\%), employment-related (19.4\%), and housing-related (48.0\%) [19]. In NHIS samples, a sizable proportion of cancer survivors ( $25.6 \%$, equivalent to 5.4 million) had changed neighborhoods after their first cancer diagnosis.

Our results expand upon the descriptive epidemiology in the current literature by quantifying the associations between multiple risk factors and neighborhood tenure and relocation. Neighborhood tenure in both cancer and non-cancer groups in general was affected by a similar set of common socioeconomic and demographic factors, including age, education, income, health insurance, and family structure. Sensitivity analyses indicated these main findings were robust. These observed associations were consistent with the set of factors for neighborhood relocation among those with cancer. For example, we found that adults with family income below the poverty threshold, with a lower level of education and without health insurance coverage were more likely to move after their first cancer diagnosis. Among cancer survivors, detailed reasons of neighborhood tenure and relocation may differ by cancer status (e.g. cancer types, cancer treatment and survival status). We found that the proportion of relocation among participants with a history of lung cancer, which has a low survival rate (5-year survival rate $\sim 20 \%$ [20]), was one quarter of that among participants with a history of cervical cancer (5-year survival rate 66\% [21]).

Despite the similarities in neighborhood tenure between people with and without a history of cancer, cancer survivors may face unique challenges. This is supported by results from the propensity-score-matched analysis, where cancer survivors experienced increased odds of shorter neighborhood tenure than their noncancer counterparts. A relocation may result from or inflict a larger health, psychosocial, and economic burden 
among cancer survivors than those without cancer. Our stratified analysis showed that unemployment status increased the odds of shorter neighborhood tenure among cancer survivors, while the opposite was true for noncancer adults. Changes in employment status may be a direct result of a cancer diagnosis and its related treatment, which tend to adversely affect cancer survivors. Work ability and performance [22, 23]. Moreover, changes in employment status may also adversely contribute to financial toxicity among cancer survivors, such as reduced income and loss of employer-sponsored health insurance coverage $[23,24]$, all of which may in turn prompt a move. For people who were already facing financial hardship predating a cancer diagnosis, relocation may add additional strain and psychosocial stress. Qualitative investigations have found a potential spiral to acute and irreversible financial stress among patients who had to relocate for specialist treatment for hematological malignancy [25]. Other studies have demonstrated extra financial burden and physiologic stress associated with cancer diagnosis and treatment that led to delaying or forgoing treatments and medications, reduced quality of life, and ultimately mortality [26-31]. However, few studies have investigated the sequelae of residential mobility among cancer patients and survivors. We were only able to find one such study, where a recent relocation (within 3 years) prior to a second cancer diagnosis was associated with an approximately $30 \%$ increased risk of late-stage presentation and a $26 \%$ increase in 10-year cancer-specific mortality, and the negative impact was larger for patients living in the least wealthy counties [6].

It stands to reason to postulate that a shorter residential tenure and neighborhood relocation may cast a stronger negative impact on the overall well-being of cancer survivors, as residential mobility is closely related to household financial hardship, disruption of care continuity, and disruption of social networks $[6-8,10]$. Alternatively, a relocation to be closer to family members and friends, closer to cancer treatment facilities, to a more affordable and/or friendly neighborhood, to be closer to a job, or a combination of these, may also help alleviate the financial and psychosocial stress among cancer survivors. Our analysis showed that those who considered their own neighborhoods to have strong social cohesion were more likely to stay in the neighborhood. This previously unreported finding may have potential implications in improving care and outcomes while reducing disparities in cancer survivorship. Indeed, longitudinal studies have shown that the overall, cardiovascular disease-specific, and cancer-specific mortality rates were positively associated with neighborhood improvement while negatively associated with neighborhood deterioration [32].

\section{Limitations}

The study shares some of the same limitations of other studies that have used NHIS data. First, the crosssectional nature of the survey and the lack of information regarding the reason for relocating prevented us from drawing causal inferences. Rather, the results are better served for hypothesis generating purposes. Second, our results are not generalizable to the institutionalized or non-civilian populations, such as adults in a skilled nursing facility or the military/veteran population. In addition, cancer survivors who were still alive at the time of the interview were different from patients with cancers with a less favorable prognosis. Cancer survivors with more advanced disease were more likely to live in nursing homes, long-term-care facilities, or hospice, and thus were not included in the survey. Mortality data were not available in the public NHIS data release, thus the subsequent health impact of neighborhood tenure and relocation on survival could not be explored in the current study, and warrants further investigation. Other factors such as availability and accessibility of oncological infrastructure, which influence residential mobility of cancer patients but were not available in the data, were not considered in the current analysis. Finally, all the measures were based on self-reported responses, and were subject to recall and response bias. Nonetheless, the large sample size and national representativeness of the NHIS data allowed us to provide the first estimate, to our knowledge, of the residential mobility patterns among adult cancer survivors. Given the dearth of information on this topic, our study lends evidence to future studies to examine detailed dynamics of residential mobility and their downstream impact on cancer survivorship.

\section{Conclusion}

With continued improvement in early detection and treatment options for cancer, the proportion of people who have had a cancer diagnosis is expected to grow. Our estimates of residential mobility among adult cancer survivors are critical to inform policies and practices aimed at improving survivorship care and outcomes as well as reducing cancer disparities. Shorter neighborhood tenure and neighborhood relocation may increase financial hardship, disrupt cancer patients' social and care support networks, and interrupt continuity of care. These negative impacts are potentially greater among those with low socioeconomic status. On the other hand, sound neighborhood built environments including high social cohesion can provide positive impacts among cancer survivors. To examine the long-term implications for health and economic well-being associated with cancer, awareness of residential mobility, an important aspect that has often been neglected, should be incorporated into medical care research and practice. 


\section{Supplementary information}

Supplementary information accompanies this paper at https://doi.org/10. 1186/s12889-020-09686-2.

Additional file 1: Table S1. Distributions of neighborhood tenure and relocation by major cancer types, NHIS 2013-2018. Table 2. Standard differences in variables before and after the propensity score matching. Table S3. Associations between shorter neighborhood tenure and cancer history status. Table S4. Factors associated with neighborhood relocation after the first cancer diagnosis, excluding those whose cancer duration and neighborhood tenure were in the same time duration category.

\section{Acknowledgements}

Not Applicable.

\section{Authors' contributions}

Study concept and design, acquisition of data, statistical analysis, and drafting of the manuscript: BL. Result interpretation: BL, FL, and FB. Critical revision of the manuscript for important intellectual content: $\mathrm{FB}, \mathrm{FL}$, and $\mathrm{BL}$. $B L$ had full access to all the data in the study and take responsibility for the integrity of the data and the accuracy of the data analysis. The authors read and approved the final manuscript.

\section{Funding}

This work was supported in part by a grant from the National Cancer Institute (1R21CA235153-01)

\section{Availability of data and materials}

Data used for this study were publicly available from the NIHS website, https://www.cdc.gov/nchs/nhis/data-questionnaires-documentation.htm

\section{Ethics approval and consent to participate}

This study does not contain any studies with human participants performed by any of the authors. This study used the publicly available data from the National Health Interview Survey (NHIS), which is regularly conducted by the U.S. Census Bureau on behalf of the National Center for Health Statistics (NCHS). Survey participants were informed about the purpose and process of the NHIS in an advance letter prior to in-person interview, and verbal consent were obtained at the time of interview. The publicly released data contain no information that could identify any individual participants.

\section{Consent for publication}

Not Applicable.

\section{Competing interests}

None to report.

\section{Author details}

'Department of Population Health Science and Policy, Icahn School of Medicine at Mount Sinai, One Gustave L. Levy Place, Box 1077, New York City, NY 10029, USA. Bureau of Cancer Epidemiology, Division of Chronic Disease Prevention, New York State Department of Health, Albany, NY, USA ${ }^{3}$ Pumphandle LLC, Portland, ME, USA.

Received: 21 May 2020 Accepted: 13 October 2020 Published online: 23 October 2020

\section{References}

1. Boscoe FP. The use of residential history in environmental health studies. Geotech Environ. 2011;4:93-110.

2. Diez Roux AV. Neighborhoods and health: where are we and were do we go from here? Rev Epidemiol Sante Publique. 2007;55(1):13-21.

3. Adler NE, Cutler DM, Fielding JE, Galea S, Glymour MM, Koh HK, Satcher D: Addressing Social Determinants of Health and Health Disparities: A Vital Direction for Health and Health Care. NAM Perspectives Discussion Paper, National Academy of Medicine, Washington, DC doi: 1031478/201609t 2016, Available at https://nam.edu/addressing-social-determinants-of-health-andhealth-disparities-a-vital-direction-for-health-and-health-care/. Accessed September 20, 2019
4. Morris T, Manley D, Sabel CE. Residential mobility: towards progress in mobility health research. Prog Hum Geogr. 2018;42(1):112-33.

5. Geronimus AT, Bound J, Ro A. Residential mobility across local areas in the United States and the geographic distribution of the healthy population. Demography. 2014;51(3):777-809.

6. Muralidhar V, Nguyen PL, Tucker-Seeley RD. Recent relocation and decreased survival following a cancer diagnosis. Prev Med. 2016;89:245-50.

7. Kent EE, Forsythe LP, Yabroff KR, Weaver KE, de Moor JS, Rodriguez JL, Rowland $\mathrm{JH}$. Are survivors who report cancer-related financial problems more likely to forgo or delay medical care? Cancer. 2013;119(20):3710-7.

8. Baugh DK, Verghese S. Migration patterns for Medicaid enrollees 2005-2007. Medicare Medicaid Res Rev. 2013;3(4):mmrr.003.04.b02. https://doi.org/10. 5600/mmrr.003.04.b02. eCollection 2013.

9. Feltbower RG, Glaser AW, Parslow RC, Kinsey SE. Geographic mobility following cancer treatment in Yorkshire, UK. Arch Dis Child. 2004;89(4):380-1.

10. Miller KD, Nogueira L, Mariotto AB, Rowland JH, Yabroff KR, Alfano CM, Jemal A, Kramer JL, Siegel RL. Cancer treatment and survivorship statistics, 2019. CA Cancer J Clin. 2019;69(5):363-85.

11. Shapiro CL. Cancer survivorship. N Engl J Med. 2018;379(25):2438-50.

12. CDC: National Health Interview Survey. NHIS Data, Questionnaires and Related Documentation. 2019, Centers for Disease Control and Prevention: Available at https://www.cdc.gov/nchs/nhis/data-questionnairesdocumentation.htm. Accessed 13 July 2019.

13. Sampson RJ, Raudenbush SW, Earls F. Neighborhoods and violent crime: a multilevel study of collective efficacy. Science. 1997;277(5328):918-24.

14. Murillo R, Echeverria S, Vasquez E. Differences in neighborhood social cohesion and aerobic physical activity by Latino subgroup. SSM Popul Health. 2016;2:536-41.

15. Coca-Perraillon M: Local and Global Optimal Propensity Score Matching. SAS Global Forum 2007:185-2007. Available at https://support.sas.com/resources/ papers/proceedings/proceedings/forum2007/2185-2007.pdf Accessed December 2016, 2019.

16. Yang D, Dalton JE: A unified approach to measuring the effect size between two groups using SAS ${ }^{\oplus}$. SAS Global Forum 2012:335-2012. Available at https://support.sas.com/resources/papers/proceedings2012/2335-2012.pdf Assessed December 2016, 2019.

17. Census: Declining Mover Rate Driven by Renters, Census Bureau Reports. 2017, United Census Bureau:Available at https://census.gov/newsroom/ press-releases/2017/mover-rates.html. Accessed March 2030, 2019.

18. Marlay MC, Fields AK: Seasonality of Moves and the Duration and Tenure of Residence: 2004. Available at https://www.censusgov/prod/2010pubs/ p70-122pdf Accessed March 30, 20192010

19. Ihrke D: Reason for Moving: 2012 to 2013. Current population reports P20574 US Census Bureau, Washington, DC 2014.

20. SEER: Cancer Stat Facts: Lung and Bronchus Cancer. The Surveillance, Epidemiology, and End Results (SEER) Program 2020:Available at https://seer. cancer.gov/statfacts/html/lungb.html. Assessed August 25, 2020.

21. SEER: Cancer Stat Facts: Cervical Cancer. The Surveillance, Epidemiology, and End Results (SEER) Program 2020:Available at https://seer.cancer.gov/ statfacts/html/cervix.html. Assessed August 25, 2020.

22. Mehnert A, de Boer A, Feuerstein M. Employment challenges for cancer survivors. Cancer. 2013;119(Suppl 11):2151-9.

23. Yabroff KR, Zheng Z, Han X. Cancer survivorship. N Engl J Med. 2019;380(14):1380-1.

24. Pearce A, Tomalin B, Kaambwa B, Horevoorts N, Duijts S, Mols F, van de Poll-Franse L, Koczwara B. Financial toxicity is more than costs of care: the relationship between employment and financial toxicity in long-term cancer survivors. J Cancer Surviv. 2019;13(1):10-20.

25. McGrath $P$. Financial distress during relocation for treatment of a hematological malignancy: findings for social work. Soc Work Health Care. 2016:55(4):265-79.

26. Weaver KE, Forsythe LP, Reeve BB, Alfano CM, Rodriguez JL, Sabatino SA, Hawkins NA, Rowland JH. Mental and physical health-related quality of life among U.S. cancer survivors: population estimates from the 2010 National health interview survey. Cancer Epidemiol Biomarkers Prev. 2012;21(11): 2108-17.

27. Zafar SY, McNeil RB, Thomas CM, Lathan CS, Ayanian JZ, Provenzale D. Population-based assessment of cancer survivors' financial burden and quality of life: a prospective cohort study. J Oncol Pract. 2015;11(2):145-50.

28. Banegas MP, Guy GP Jr, de Moor JS, Ekwueme DU, Virgo KS, Kent EE, Nutt S, Zheng Z, Rechis R, Yabroff KR. For working-age Cancer survivors, medical debt and bankruptcy create financial hardships. Health Aff (Millwood). 2016; 35(1):54-61. 
29. Schwartz RM, Ornstein KA, Liu B, Alpert N, Bevilacqua KG, Taioli E. Change in quality of life after a Cancer diagnosis among a nationally representative cohort of older adults in the US. Cancer Investig. 2019;37(7):299-310.

30. Altice CK, Banegas MP, Tucker-Seeley RD, Yabroff KR: Financial Hardships Experienced by Cancer Survivors: A Systematic Review. J Natl Cancer Inst 2017, 109(2):https://www.ncbi.nlm.nih.gov/pubmed/27754926. Assessed September 27754920, 27752019.

31. Zheng Z, Han X, Guy GP Jr, Davidoff AJ, Li C, Banegas MP, Ekwueme DU, Yabroff KR, Jemal A. Do cancer survivors change their prescription drug use for financial reasons? Findings from a nationally representative sample in the United States. Cancer. 2017:123(8):1453-63.

32. Xiao Q, Berrigan D, Powell-Wiley TM, Matthews CE. Ten-year change in neighborhood socioeconomic deprivation and rates of Total, cardiovascular disease, and Cancer mortality in older US adults. Am J Epidemiol. 2018; 187(12):2642-50

\section{Publisher's Note}

Springer Nature remains neutral with regard to jurisdictional claims in published maps and institutional affiliations.

Ready to submit your research? Choose BMC and benefit from:

- fast, convenient online submission

- thorough peer review by experienced researchers in your field

- rapid publication on acceptance

- support for research data, including large and complex data types

- gold Open Access which fosters wider collaboration and increased citations

- maximum visibility for your research: over $100 \mathrm{M}$ website views per year

At BMC, research is always in progress.

Learn more biomedcentral.com/submissions 